\title{
O convívio acadêmico: representações sociais de alunos com Necessidades Educacionais Especiais
}

\author{
Zenilda Nogueira Sales* \\ Ramon Missias Moreira** \\ Edvaldo Souza Couto ${ }^{* * *}$
}

\section{Resumo}

É evidente o papel da universidade e seu compromisso de proporcionar uma educação mais justa e democrática para todos os jovens e contribuir para a elaboração de conhecimento e efetivação de políticas inclusivas. Este estudo objetivou apreender e analisar as representaçôes sociais de alunos com necessidades educacionais especiais no ensino superior sobre o convívio acadêmico. $\mathrm{O}$ método usado foi o estudo de caso, descritivo-exploratório, qualitativo, fundamentado na abordagem processual da Teoria das Representaçôes Sociais, realizado numa universidade estadual da Bahia. Foi utilizada como técnica de coleta a entrevista semiestruturada, como instrumento o questionário. Para analisar os resultados foi utilizada a Análise de Conteúdo Temática Categorial, de onde emergiram as seguintes categorias e subcategorias: Dificuldades e Limitaçôes (Barreiras Atitudinais; Barreiras Pedagógicas) e Relações Interpessoais (Relação Interpessoal com os Colegas; Relação Interpessoal com os Professores). Evidenciou-se despreparo da universidade e de seus profissionais, no sentido de proporcionar a inclusão e atendimento adequado às necessidades especiais dos alunos. É necessário que a universidade invista na definiçấo de políticas institucionais para construção de açôes inclusivas, que beneficiem o processo ensino/aprendizagem e a interaçáo social dos alunos com necessidades educacionais especiais.

Palavras-chave: Inclusão; Necessidades Educacionais Especiais; Ensino superior.

\footnotetext{
* Professora doutora da Universidade Estadual do Sudoeste da Bahia, Jequie, Bahia, Brasil.

** Doutorando em Educação pela Universidade Federal da Bahia, Salvador, Bahia, Brasil.

*** Professor doutor da Universidade Federal da Bahia, Salvador, Bahia, Brasil.
} 


\section{The academic living: social representations of students with Special Educational Needs}

\section{Abstract}

Clearly the role of the university and its commitment to providing a more equitable and democratic education for all young people and contribute to the development of knowledge and realization of inclusive policies. This study aimed to apprehend and analyze the social representations of students with special educational needs in higher education on academic living. The method used was the case study, descriptive and exploratory study, qualitative, grounded in the procedural approach of the Social Representations Theory, realized in a state university of Bahia. To collect the data was used as technique the semi-structured interview and the questionnaire as instrument. To analyze the results we used the technique of Thematic Content Analysis Categorical, from which emerged the following categories and subcategories: Difficulties and Limitations (Attitudinal Barriers, Barriers Pedagogical) and Interpersonal Relationships (Interpersonal Relation with Colleagues; Interpersonal Relationship with Teachers). Was evidenced unpreparedness of the university, and of the professionals who are part of them, in the sense of to provide the inclusion and appropriate care to students with special educational needs. It is necessary that the university invests in definition of institutional policies to construction of inclusive actions that benefit the teaching/learning process and social interaction of students with special educational needs.

Keywords: Inclusion; Special Educational Needs; Higher education.

\section{Introdução}

Este estudo versa sobre as Representaçóes Sociais concernentes à inclusão de alunos com Necessidades Educacionais Especiais (NEE) no ensino superior, com vistas a realizar um diagnóstico situacional de acordo com a percepçáo desses sujeitos sociais.

É evidente o papel da universidade e seu compromisso de proporcionar uma educação mais justa e democrática para todos os jovens e contribuir para a elaboração de conhecimento e efetivação de políticas inclusivas. A Educação Inclusiva é uma política educacional garantida por lei e deve ser implementada de maneira que forneça aos estudantes com NEE, seja no ensino fundamental, no ensino médio ou no ensino superior, uma resposta educativa adequada às suas necessidades e favoreça a sua aprendizagem e socialização (CASTANHO, 2007).

Destarte, as transformaçóes do sistema educacional brasileiro trazem para as políticas públicas de educação superior e para a cultura universitária dois grandes desafios: a garantia do acesso e a permanência de pessoas com deficiência nas universidades visando a promoção da aprendizagem (BRUNO, 2010). Observando a trajetória do acesso à universidade pelas pessoas com deficiência, verificamos que até 
o início da década de 1980 poucas dessas pessoas tinham acesso à Educação Superior no Brasil. Isto estava associado ao não acesso dessa população a Educação Básica e aos serviços de reabilitação, o que indica nesse período sua exclusão dos direitos sociais básicos (VALDÉS, 2005).

Nesse mesmo sentido, o acesso de jovens e adultos com deficiência ao ensino superior advém dessa dificuldade de acesso ao conhecimento no ensino fundamental e médio. Grande parte dessas dificuldades incide no processo seletivo para o vestibular, onde é necessário ter adquirido determinadas competências e conhecimentos anteriores para o acesso à Universidade (TORRES, 2002). E depois do ingresso observa-se que, na maioria das vezes, são os alunos com NEE que têm que se adaptar à universidade, a qual deveria estabelecer a inclusão desses alunos e se reestruturar, física e humanamente, para recepcioná-los e auxiliá-los no seu processo de ensino -aprendizagem.

Esse é o desafio a ser vencido pela universidade na efetivação da política de inclusão de alunos com NEE no sistema regular de ensino (GLAT; PLETSCH, 2004). Para isso, deverá estabelecer açóes no âmbito do ensino, da pesquisa e da extensão que contribuam para que a escola possa ser resignificada. Afinal, "o papel social da universidade é fundamental, ela não poderá ser indiferente à diferença, é necessário que se busque um processo educacional mais justo e democrático" (ROCHA; MIRANDA, 2009, p. 32).

No que tange à inclusão social de alunos com necessidades especiais no sistema regular de ensino tem sido, sem dúvida, a questấo referente à educaçáo especial mais discutida no Brasil nas últimas décadas. Este tema, que por tanto tempo ficou restrito ao debate em congressos e textos da literatura especializada, hoje se torna proposta de intervenção governamental da administraçáo centralizada e descentralizada, fomentada e regulamentada pela legislação em vigor e determinante das políticas públicas educacionais tanto em nível federal, quanto estadual e municipal (RAMOS, 2010).

Nesse sentido, o tema inclusão social tem gerado inúmeras discussões, das quais emergem muitas concepçôes e abordagens. Nesse contexto, as instituiçóes, empresas e sociedade civil organizada, juntamente com as pessoas com deficiência, têm o direito de se posicionarem diante da temática, de maneira crítica e pró-ativa. Assim, enquanto agentes e ator principal de tal processo, devem propor alternativas, buscar parecerias e apontar caminhos para que essa inclusão seja possível e para que ela, de fato, ocorra em uma dimensão que transcenda o nível do discurso e alcance a prática. Além disso, também é importante o desenvolvimento de pesquisas que abordem temas referentes às demandas das pessoas com deficiências consequentemente com necessidades educacionais especiais (GLAT, 2003).

A percepção social dos alunos com NEE deve ser respeitada e tomada como base para (re)solucionar essa problemática da inclusão. Nessa perspectiva, este estudo teve como objetivo apreender e analisar as representaçóes de alunos com necessidades educacionais especiais no ensino superior sobre o convívio acadêmico. 


\section{Aporte teórico}

A concepção sobre a Teoria das Representaçóes Sociais (TRS) que é elaborada por Moscovici busca uma singularidade, a partir da construção de uma cognição verdadeiramente psicossocial, ao tempo em que procura problematizar os nexos entre os sujeitos e a sociedade, distanciando-se da visão sociológica de Durkheim e da perspectiva da Psicologia Social (ALVES-MAZZOTTI, 2008). Apesar da visão diferente diante dos fatos, Durkheim definiu passos importantes para a construção do conhecimento científico à medida em que delimitou a percepção do coletivo como princípio de nossa vida e nossa história, a partir das produçóes mentais e sociais, caracterizando-se como Representaçôes Sociais (MOSCOVICI, 2009).

De acordo com Castro (2002), a TRS é percebida por Moscovici como decorrência da relaçáo entre os sujeitos com o meio social, que se encontra em movimento. Podemos afirmar, em síntese, que se trata de representações presentes no interior dos indivíduos, mas com características sociais, que fazem parte do senso comum.

A partir desses pressupostos, a TRS foi selecionada para dar suporte e embasamento teórico a este artigo, vez que se acredita que contribuiu para o entendimento e compreensão dos desafios, atos e situaçóes que envolvem o objeto social dessa pesquisa, possibilitando, lidar com os fenômenos que são observáveis sob o prisma de diversas óticas, partindo de aspectos psicossociais, tais como: valores, crenças de vida e religiosas, informativos, ideologias, atitudes, opiniōes, dentre outros. As representaçôes sociais são entendidas por Moscovici como entes quase tangíveis, que se cristalizam incessantemente através das falas, dos encontros, dos gestos, isto é, podemos conceituá-las e tipificá-las. Portanto, a TRS tem como objetivo maior compreender a variedade dos saberes do senso comum em sua interface com a comunicação, pensamento e gênese dessa percepção (MOSCOVICI, 2009).

Nesse contexto, percebe-se que as transformaçóes ocorridas no sistema educacional brasileiro trazem para as políticas públicas de educação superior e para a cultura universitária, dois grandes desafios: o primeiro, a garantia do acesso; e o segundo, a promoção da aprendizagem para permanência de pessoas com deficiência nas universidades públicas e privadas em nosso país (BUENO, 2002). Observa-se que um dos debates mais recorrentes das últimas décadas tem sido a inclusão de pessoas em situação de deficiência. Apesar das amplas reflexões e do amparo legal, as mudanças introduzidas na escola ainda são pouco significativas, o que nos permite afirmar que a política de educação inclusiva ainda é um ideal a ser alcançado. Uma escola para todos, implicando num sistema educacional que reconheça e atenda às diferenças, respeitando as necessidades de qualquer dos alunos. Sob essa ótica não apenas pessoas com deficiência seriam ajudadas e sim todos os alunos, que, por inúmeras causas, endógenas ou exógenas, temporárias ou permanentes, apresentem dificuldades de aprendizagem ou no desenvolvimento (CARVALHO, 2004).

Destarte, o tema inclusão social tem gerado inúmeras discussões, das quais emergem muitas concepçóes e abordagens. Assim, o ensino superior, enquanto agente e ator principal diante de tal processo, deve propor alternativas, buscar parecerias e apontar caminhos para que essa inclusão seja possível e para que ela, de fato, ocorra 
em uma dimensão que transcenda o nível do discurso e alcance a prática. Além disso, também é importante o desenvolvimento de pesquisas que abordem temas referentes às demandas das pessoas com deficiências, consequentemente com necessidades educacionais especiais.

\section{Metodologia}

Trata-se de um estudo de caso, de cunho exploratório e descritivo, com abordagem qualitativa, que teve como lócus a Universidade Estadual do Sudoeste da Bahia (UESB), realizado em parceria com o Programa de Pós-graduação em Educação da Faculdade de Educação da Universidade Federal da Bahia (UFBA). Ancorou-se na abordagem dimensional ou processual (JODELET, 2001) da Teoria das Representaçôes Sociais (MOSCOVICI, 2009), resgatando o princípio de coerência que estrutura os campos de uma representação: organização sociocultural, atitudes, modelos normativos ou ainda esquemas cognitivos.

A pesquisa foi realizada na UESB, nos Campi de Vitória da Conquista (VC) e Jequié (JQ), cidades localizadas na regiáo Sudoeste do Estado da Bahia, Brasil. Foi realizado levantamento do quantitativo de alunos que ingressaram na referida universidade através das cotas para indivíduos com deficiência e regularmente matriculados na Secretaria Setorial de Cursos. Participaram da pesquisa 11 alunos com NEE, matriculados nos cursos de graduação desses campi.

Para coleta de dados utilizou-se a técnica de entrevista semiestruturada baseada no roteiro de entrevista aplicado em estudo da Universidade e Centro Universitário de Santa Maria - RS (CASTANHO, 2007) que utilizou quatro eixos principais: vida acadêmica, ensino-aprendizagem, relaçóes interpessoais e o ambiente educacional e o aluno com necessidades educacionais especiais, além de um questionário biosociodemográfico. No nosso recorte metodológico, enfatizamos as relaçóes interpessoais entre alunos e alunos e professores; e, também, dificuldades e limitaçóes atitudinais e pedagógicas.

Para aplicação do instrumento realizou-se uma visita prévia ao campus de $\mathrm{VC}$, onde fizemos o agendamento das entrevistas com cinco alunos. No campus de JQ, foi realizada uma reunião com 18 alunos, mas somente seis se dispuseram a participar da pesquisa. Após o cumprimento desta etapa foi elaborado uma agenda para realizaçáo das entrevistas nos dois campi. A coleta de dados deu-se no segundo semestre de 2011, logo após o parecer do Comitê de Ética da UESB, sob protocolo no. 036/2011. Os alunos só participaram após a assinatura do Termo de Consentimento Livre Esclarecido. É válido ressaltar que esse artigo foi extraído do Relatório de Pós Doutorado em Educação e Diversidade apresentado ao Programa de Pós Graduação em Educação da UFBA, em 2012.

As entrevistas foram gravadas com auxílio de um gravador, realizadas individualmente. As falas foram transcritas na íntegra, ipsis litteris, da forma como foram expressadas pelos participantes. 
Para tratamento dos dados utilizou-se como suporte teórico a Técnica de Análise de Conteúdo Temático Categorial (BARDIN, 2011) e analisados através da ancoragem e objetivação (JODELET, 2001; MOSCOVICI, 2009). O corpus foi constituído pelas onze entrevistas e após a transcrição realizou-se a leitura flutuante e subsequente leitura exaustiva para se chegar à definição das categorias empíricas emergentes. Após recorte e classificação, foi realizada a decomposição das falas dos sujeitos da pesquisa e efetuou-se a codificação dos temas, agrupando-os em $02 \mathrm{ca}-$ tegorias simbólicas e 04 subcategorias, e posteriormente inferência e interpretações.

\section{Resultados e discussão}

Participaram da pesquisa onze alunos com NEE, sendo seis do campus JQ e cinco do campus VC. Do total de onze alunos, seis sáo do sexo feminino, cinco do sexo masculino, com a idade variando entre 20 a 35 anos. Os onze entrevistados estấo distribuídos em diferentes cursos: Letras, Pedagogia, Enfermagem, Fisioterapia, Medicina, História, Direito e Comunicação Social.

Em relação à deficiência, oito tem Deficiência Visual (DV), sendo que destes um tem multipla deficiência, Visual e Física, um tem deficiência auditiva unilateral, dois têm deficiência física. Os participantes foram identificados ficticiamente pelas denominaçóes alfanuméricas de $\mathrm{A} 1$ à $\mathrm{A} 11$, entre parênteses, ao final de cada fala.

\section{Categoria 1: Dificuldades e Limitações}

A maioria dos entrevistados fez alusão a algum tipo de dificuldade ou limitação enfrentada, seja em relação às atitudes das pessoas envolvidas no seu convívio acadêmico ou em relação à falta de recursos materiais e humanos especializados para o seu apoio pedagógico.

Para melhor compreensão desse fenômeno, esta categoria foi decomposta em duas subcategorias temáticas, as quais estão dispostas a seguir.

\section{Subcategoria 1: Barreiras Atitudinais}

Nesta subcategoria os participantes relatam as barreiras atitudinais enfrentadas no seu cotidiano acadêmico. Os recortes das falas do aluno A1 remetem-nos à atitude do professor em desconfiar do aluno com DV: "são as barreiras atitudinais [...] o professor não conhecer a realidade do $\mathrm{DV}$, ele não compreende o processo, logo no inicio do curso teve professores que tinham uma certa desconfiança, queria fazer a prova oral comigo (A1)".

No nosso entendimento esta desconfiança é decorrente da falta de conhecimento do professor, e muitas vezes, reporta a um comportamento discriminatório e de juízo de valor da capacidade intelectual do aluno.

Os alunos A3 e A9 explicitam o comportamento de alguns membros da comunidade acadêmica ao percebê-lo como diferente: "no começo era muito difícil porque a gente não tinha um lugar pra realizar as atividades era obrigada a gente tá nos corredores da universidade, pessoas no começo olhava a gente com diferença entấo isso aconteceu muito (A3 e A9)". 
A categoria do estranho, do desvio, para Amaral (1994), no campo biológico, está presente no corpo seja pela falta ou excesso de alguma coisa. Representa algo que foge aos padróes tidos como: belo, perfeito e almejados pela sociedade.

Os estereótipos são crenças que nos são transmitidas pela influência social, a partir dos meio de comunicação, tendo sua gênese no ambiente familiar, grupal e nas concepçóes de mundo e do contexto histórico e cultural de cada indivíduo (VALA; MONTEIRO, 2002). Nessa perspectiva, os alunos com DV se apresentam para o outro como uma ameaça, por vez a diferença acaba suscitando preconceito, estereótipos, atitudes ou comportamentos que acabam por legitimar a deficiência e a exclusão.

Aquiescendo Moscovici (2009), no processo de comunicação social as representaçóes sociais circulam, cristalizam-se no universo das interaçóes sociais e se materializam nas práticas cotidianas. Essas representaçóes presentes no dia-a-dia universitário são concebidas por atitudes e comportamentos discriminatórios, que levam à segregação desses alunos.

Da mesma forma que o imaginário social, as representaçóes sociais apresentam caráter coletivo, construídas por uma mistura de conceitos, valores, imagens e percepçóes compartilhadas por vários grupos e transmitidas de geração a geração, seja no ambiente familiar, na escola e nos diversos grupos de pertença (MOREIRA, 2003).

Diversas são as barreiras e obstáculos vivenciados no cotidiano dos alunos com deficiência física e que se tornam um alicerce ancorador das suas representaçóes sociais, sejam eles naturais, físicos e arquitetônicos. Entretanto, há outro tipo de obstáculo muito mais sutil, que apesar de ser menos palpável, representa uma maneira cruel, desumana e excludente de comprometer e inviabilizar a permanência do aluno com deficiência na sala de aula. Trata-se do preconceito, que é uma barreira atitudinal expressada implícita e explicitamente e que se camufla em diferentes disfarces, impedindo brutalmente o relacionamento e o convívio do aluno com NEE com as pessoas (KOHATSU, 2003).

O entrevistado A9, enquanto pessoa com deficiência física, e para sua locomoção precisa da cadeira de rodas, expressa a sua experiência no campus universitário de VC: "ali no módulo têm escada, eu tive que subir a escada todinha, fui entrar com a cadeira no banheiro, não entra cadeira de roda [...] Não tem rampa, não tem elevador, não tem nada [...] o banheiro também não é adaptado (A9)".

A aluna A11, na condição de DV, salienta que não tem problema de locomoção motora, mais enquanto DV percebe que falta estrutura física e espaço adaptados: "eu não tenho problema com a locomoção motora, mas eu sinto que tem muitos degraus [...] a biblioteca onde fica o núcleo, a inclusão está mais dentro do núcleo e não na universidade como um todo (A11)".

Corroborando com o estudo realizado por Moreira (2003), as barreiras arquitetônicas são consideradas um grande entrave para as pessoas com deficiência física, um problema que deve ser revisto nas instituiçóes de ensino superior, tonando-se evidente as construçôes civis dos prédios e módulos escolares apresentam grandes 
entraves físicos, que vão desde a falta de rampas e corrimóes nas escadas, elevadores, banheiros adaptados, portas que não permitem a entrada de cadeiras de roda, dentre outros.

Dessa maneira, infere-se que a atitude reflexiva da educação apenas consolidar-se-á com o desenvolvimento de uma educação voltada para a inclusão e para a formação do cidadão e não à exclusão. Por conseguinte, para alcançar esse objetivo será necessário que todos os atores sociais envolvidos direta e indiretamente no cenário educativo contribuam significativamente com ideias, reflexôes, açôes e práticas inclusivas no processo educacional como um todo, pautando-se no respeito, na diversidade, na defesa da igualdade, na aceitação do próximo como a si mesmo e na pluralidade cultural (CRUZ, 2012).

\section{Subcategoria 2: Barreiras Pedagógicas}

Os alunos A9, A10 e A11 destacaram a dificuldade em relação ao apoio educacional. Essas barreiras encontradas estão relacionadas às práticas pedagógicas: "falta de livros, recursos humanos disponíveis para atender a demanda do aluno, falta de sensibilidade por parte do professor na disponibilizaçáo do material didático para o aluno com DV [...] (A9, A10 e A11)".

A presença de alunos com NEE no ensino superior remete à reflexão de que a educação inclusiva requer uma reconstrução dos sistemas de ensino, necessitando superação das barreiras pedagógicas, as quais não se limitam à infraestrutura física necessária. Estudo realizado com professores sobre a inclusão de uma aluna cega, evidenciou a carência de materiais didáticos, além do despreparo docente para a interação com as necessidades específicas, resultando no insucesso na formaçáa da discente cega (REGIANI; MÓL, 2013).

As dificuldades referentes ao processo de ensino e aprendizagem provavelmente seriam minimizadas caso a universidade disponibilizasse tecnologias assistivas, estruturas de apoio necessário para atender às demandas desses alunos quanto aos conhecimentos básicos sobre as deficiências.

\section{Categoria 2: Relações Interpessoais}

É através da interação e das relaçôes interpessoais que o indivíduo tem a possibilidade de exteriorizar a sua subjetividade. Compartilhando dessa intersubjetividade o ser humano terá o verdadeiro conhecimento sobre a realidade vivenciada, sendo capaz de perceber a diferença entre a sua realidade e as outras (ALEXANDRE, 2004).

Nesse sentido, as representaçôes sociais, como um conjunto de conceitos, frases e explicaçôes inseridas na vida diária, evidenciam o constructo elaborado a partir do convívio e comunicaçôes interpessoais entre os alunos com NEE e os professores e com os demais colegas de classe (MOSCOVICI, 2009). 


\section{Subcategoria 1: Relação Interpessoal com os Colegas}

Conforme fragmentos das falas dos entrevistados, o convívio com os colegas é de forma ordeira, sem preconceitos, não são tratados de maneira indistinta aos demais colegas e suas limitaçóes são respeitadas.

Bom, a princípio é muito boa, assim eu nunca sofri preconceito mesmo com relação á deficiência [...] (A1, A2).

Ótima, eles me tratam super bem a gente tem uma relação muito boa [...] (A3, A4).

Tudo tranquilo, não tem diferença nenhuma, todos tratam da mesma forma [...] (A5, A6, A7).

Eu me relaciono bem com todo mundo agora sempre tem colegas que a gente tem mais afinidade e esses colegas me apoiam [...] (A10, A11).

A legislação escolar brasileira preconiza a importância da implementação da educação inclusiva não apenas para o benefício dos alunos com NEE, mas também como uma educação que promova a formação de todos os alunos e um bom relacionamento entre eles. A escola deve incentivar o aprendizado, o desenvolvimento de habilidades e, especialmente, o de socialização e convívio dos colegas com deficiência ou problemas no desenvolvimento (CROCHÍK et al., 2013) com os 'alunos ditos normais'.

O aluno A8 tem DF e DV, é homossexual, e se queixa de discriminação e preconceito. As práticas discriminatórias estáo prese ntes em toda parte da sociedade. Entende-se que, o que está na sua gênese é o medo em não saber lidar com a diferença.

Eu me relaciono muito bem com alguns, tem uns que vira a cara, me respeita agora assim, sabe aquela coisa falsa, [...] eu fui apresentar o trabalho, um seminário teve uns que ficou rindo de mim, pela minha voz, porque não é igual uma voz de homem, é complicado [...] (A8).

Para Lima (2002) tal atitude dos colegas de A8 é de duplo preconceito, de estereótipos, como crença social sobre o traço comum do mesmo, crenças essas disseminadas pela sociedade.

Esse caráter integrativo torna-se condição sine qua non para os alunos com NEE, que necessitam cada vez mais serem estimulados a aprender a fazer e ensinar aos colegas a conviver com a diversidade.

O sentimento de aceitação, entendida como inclusão da diversidade, influencia de forma positiva no desenvolvimento acadêmico do aluno com NEE. A rejeiçâo gera um sentimento de inferioridade e incapacidade, repercutindo negativamente nas dimensóes processuais da aprendizagem, podendo dificultar ou bloquear esse processo (CARVALHO, 2013). 


\section{Subcategoria 2: Relação Interpessoal com os Professores}

$\mathrm{Na}$ subcategoria relação interpessoal com o professor houve uma unanimidade, na qual todos os entrevistados disseram ter um bom relacionamento com os professores. Entretanto, percebe-se em algumas falas queixas em relação à falta de preparo e/ou sensibilidade por parte de algum professor.

A participante A1 salienta que na maioria das vezes é uma relação boa, caso o professor manifeste o desejo de aprender com ela, pois a falta de conhecimento ao lidar com a deficiência visual dificulta o processo ensino aprendizagem. Argumenta ainda que se torna difícil o relacionamento quando o professor não demonstra nenhum tipo de interesse sobre a situaçáo do aluno com deficiência.

Boa, uma boa convivência com os professores, aqueles que tiveram a disponibilidade, a boa vontade de aprender comigo, conhece a realidade de um deficiente, mas só em ele ter a disponibilidade e a boa vontade de aprender de se adaptar, de querer conhecer, de querer é auxiliar [...]. A partir do momento que o professor não se dispóe, não procura saber não quer nem saber, não é aberto pra conhecer, novas realidades, então se torna difícil [....] (A1).

Ainda no tocante ao relacionamento interpessoal entre o professor e o aluno, os entrevistados fizeram alusão à boa convivência com os professores: "Ótima, nunca tive nenhum embate não [...] normal como qualquer outra estudante (A2; A3, A5, A9); É tudo ok! (A8)".

O aluno A4, enfatiza que sua relação é boa, contudo faz uma ressalva: "os professores também não tem, eu acho que não tem noção que eu sou deficiente auditivo, até mesmo porque eles não têm, não é sabido para eles que eu passei por cotas de deficiente". Neste sentido fica a dúvida quanto à relação professor/aluno. Também fica claro que o próprio aluno omite a sua condição de pessoa com deficiência auditiva, talvez por receio do preconceito ou discriminação por parte dos professores.

Os alunos que destacaram o apoio de alguns professores com mais veemência foram, A6, A7 e A10, os demais relataram atos isolados.

a relação com os professores são boas [...]. Assim, todos sempre estáo perguntando do que eu estou precisando (A6).

no caso eu tenho uma professora que no início da aula, ela entra na sala ela já começa a aula lembrando se dispondo [...], esclarece para a turma que eles deveriam fazer o trabalho sempre se lembrando de que eu estou na sala [...] (A7).

depende do professor, tem professor que é mais aberto entrega a referência, deixa lá no núcleo, deixa o texto no núcleo, agora tem professor que é mais fechado (A10).

Segundo os depoimentos dos pesquisados, os professores têm se mostraram abertos e dispostos a auxiliá-los atendendo às solicitaçôes dos alunos, realizando modificaçôes na didática pedagógica, minimizando as dificuldades e limitaçôes vivenciadas por causa da deficiência. 
A aluna A11 fala da falta de informação por parte de alguns professores em relação ao acesso do discente com deficiência à universidade, salienta ainda que não sabe se é ela que vai ter que se adaptar ao método pedagógico do professor ou se é o professor que vai buscar práticas pedagógicas que favoreçam o processo de ensino/ aprendizagem da mesma: "[...] os professores que agora nesse segundo semestre, não sei se eu que estou me adaptando a eles, ou se eles se adaptando a mim [...] (A11)".

Cabe salientar que é essencial que os professores, sobretudo aqueles que têm alunos com NEE, recebam auxílio de profissionais especializados na área. Também se faz necessário derrubar barreiras pré-concebidas e apreciar novas estratégias para um prática pedagógica pró-ativa e acessível a todos.

Essa mudança de atitude pode ser considerada como aprendidas, alteradas, a partir de um processo avaliativo, que pode ser de diversos tipos no domínio cognitivo, afetivo ou comportamental. Neste estudo foi considerado como atitude comportamental, que permite uma das funçôes da representação social que é a orientação do saber, o que guia comportamentos e práticas, permitindo a posteriori a justificativa das tomadas de posiçóes e de comportamento desses professores frente ao processo de ensino e aprendizagem e a relação interpessoal professor/aluno (LIMA, 2013).

\section{Considerações finais}

Sabe-se que para fazer acontecer a inclusão não basta apenas cumprir os decretos e leis, é preciso esforço de toda comunidade acadêmica e sociedade de modo geral para uma inclusão não "ideal", mas, satisfatória. A ancoragem possibilitou uma maior aproximaçáo com o convívio acadêmico dos alunos com NEE, além de evidenciar o despreparo dos professores, da universidade e de outros alunos sobre a inclusão e aceitação da diversidade. Através da objetivação, tornou-se explícito que os comportamentos, estereótipos e atitudes frente aos alunos com NEE aumentam os obstáculos para o aluno com deficiência, acentuando a discriminaçáo e preconceitos, levando à segregação.

É pertinente ressaltar que a universidade, por fazer parte da sociedade, deve estar aparelhada para receber adequadamente alunos com NEE e promover a sua inclusáo e socialização, bem como para mantê-lo com sucesso em seu convívio acadêmico, sem barreiras que levam ao constrangimento, à dificuldade e bloqueio no processo ensino e aprendizagem. Além disso, é conexo aludir que boas relaçóes interpessoais entre alunos e alunos e professores são fundamentais para êxito nesse processo inclusivo. Nessa perspectiva, também fazem-se necessários investimentos nas questóes didático-pedagógicas para que o professor sinta-se instrumentalizado para atender às necessidades de todos os alunos, independente das dificuldades e limitaçóes apresentadas por cada um.

Reforça-se a complexidade do tema pesquisado e a necessidade de novas investigaçóes e olhares com aprofundamento real sobre a questão da inclusão no ensino superior. Nesse ínterim, no que diz respeito às pesquisas na área da educaçáo inclusiva, percebemos que existiu um grande avanço e crescimento. Acredita-se, portanto, que estudos como esse ajudam a fundamentar e direcionar as políticas de inclusão e 
também, as ações e intervenções dos pesquisadores, profissionais da educação e toda a sociedade frente aos dilemas e desafios imbuídos nesse processo.

\section{Referências}

ALEXANDRE, M. Representaçáo social: uma genealogia do conceito. Comum. Rio de Janeiro: v. 10, n. 23. p. 122-38, 2004.

ALVES-MAZZOTTI, A. J. Representações: aspectos teóricos e aplicaçōes à educação. Revista Múltiplas Leituras, v. 1, n. 1, 2008.

AMARAL, L. A. Corpo Desviante/Olhar Perplexo. Psicologia USP, S. Paulo, 5(1/2). p. 245-266, 1994.

BARDIN, L. Análise de Conteúdo. Lisboa: Ediçôes 70, 2011.

BUENO, J. G. S. A educaçáo especial nas universidades brasileiras. Brasília: MEC/SEESP, 2002.

BRUNO, M. M. G. A Inclusáo de pessoas com deficiência no ensino superior: algumas reflexōes sobre os marcos normativos, a cultura e a prática pedagógica. 2010. Disponível em: <http://www.ufgd.edu.br/faed/nefope/downloads/livro-educacao-basica-discursos-e-praticas-politico-normativas-e-interpretativa>. Acesso em: 13 mar. 2014

CARVALHO, R. E. Educação inclusiva e a criação de vínculos: um novo olhar. Fed. Nac. das Apaes (Fenapaes). Brasília: v. 1, n. 1, p. 19-32, 2013. Disponível em: <http://apaeciencia.org.br/index.php/revista/article/ view/7/11>. Acesso em: 13 mar. 2014.

Educação Inclusiva: com os Pingos nos Is. Porto Alegre: Mediação, 2004.

CASTANHO, D. M. Política para inclusáo de alunos com necessidades educacionais especiais: um estudo em universidades e centro universitário de Santa Maria - RS. 127 f. Dissertação (Mestrado em Educação UFSM). Santa Maria, RS, 2007.

CASTRO, P. Notas para uma leitura da teoria das representaçóes sociais em Serge Moscovici. Análise social. v. XXXVII n. 164, 2002.

CROCHÍK, J. L. et al. Educação inclusiva: escolha e rejeição entre alunos. Psicologia \& Sociedade. v. 25, n.1, p. 174-184, 2013.

CRUZ, D. L. M. N. As contribuiçốes do professor para a inclusáo de alunos com necessidades educacionais especiais nas aulas de educação física do IFB - campus Planaltina. (Trabalho de Conclusão de Curso). Brasília: Universidade de Brasília, Faculdade de Educação Física, 2012.

GLAT, R. Políticas educacionais e a formação de professores para a educação inclusiva no Brasil. Revista Integraçáo, v. 24, n. 14, 2003.

GLAT, R.; PLETSCH, M. D. O papel da universidade frente às políticas públicas para educação inclusiva. Revista Benjamin Constant, v. 2, n. 8, 2004.

JODELET. D. (Org.). As representaçóes sociais. Rio de Janeiro: EDUERJ; 2001.

KOHATSU, L. N. O preconceito na escola especial. In: MARQUEZINE, M. C.; ALMEIDA, M. A.; TANAKA, E. D. O. (Orgs.). Educaçáo especial: políticas públicas e concepções sobre deficiência. Londrina: Eduel, 2003.

LIMA, L. P. Atitudes: estrutura e mudança. In: VALA, J.; MONTEIRO, M. B. (Orgs.). Psicologia social. 9. ed. Lisboa: Fundação Calouste Gulbenkian, 2013.

MOSCOVICI. S. Representaçóes sociais: investigaçôes em psicologia social. Petrópolis: Vozes; 2009.

MOREIRA, L. C. A universidade e o aluno com necessidades educativas especiais: reflexôes e proposiçóes. In: RIBEIRO, M. L. S.; BAUMEL, R. C. R. C. (Orgs.). Educaçáo especial: do querer ao fazer. São Paulo: Avercamp, 2003.

RAMOS, R. Inclusão na Prática: Estratégias Eficazes Para a Educação Inclusiva. 1. ed. São Paulo: Summus, 2010.

REGIANI, A. M.; MÓL, G. S. Inclusão de uma aluna cega em um curso de licenciatura em química. Ciência \& educaçáo (Bauru). Bauru: v. 19, n. 1, 2013. 
TORRES, E. F. As perspectivas de acesso ao Ensino Superior de jovens e adultos da Educaçáo Especial. Florianópolis, 2002. 196f. Tese (Doutorado em Engenharia de Produção). UFSC, 2002.

VALDÉS, M. T. S. A inclusáo de pessoas com deficiência no ensino superior no Brasil caminhos e desafios. Fortaleza: EDUECE 2006. Brasília, 2005.

VALA, J.; MONTEIRO, M. B. (Eds.). Psicologia social. 9. ed. Lisboa: Fundação Calouste Gulbenkian, 2013.

\section{Correspondência}

Zenilda Nogueira Sales - Universidade Estadual do Sudoeste da Bahia, Faculdade de Enfermagem de Jequié. Av. José Moreira Sobrinho, s/n, Jequiezinho, CEP: 45206-506 - Jequie, Bahia - Brasil.

E-mail: zenysalles@gmail.com - ramonefisica@hotmail.com - edvaldosouzacouto@gmail.com

Recebido em 07 de abril de 2015

Aprovado em 18 de novembro de 2015 
